\title{
Aligning the Nigerian petrochemical industry to oil and gas industry needs
}

\author{
Ajee Mamman \\ Ryemex Nigeria Ltd, Plot 67 Trans Amadi Industrial Layout, Port Harcourt, Rivers State, Nigeria
}

Email address:

ajee@ryemex.com

To cite this article:

Ajee Mamman. Aligning the Nigerian Petrochemical Industry to Oil and Gas Industry Needs. American Journal of Chemical Engineering. Special Issue: Developments in Petroleum Refining and Petrochemical Sector of the Oil and Gas Industry. Vol. 3, No. 2-1, 2015, pp. 18-24. doi: 10.11648/j.ajche.s.2015030201.13

\begin{abstract}
Nigeria is Africa's largest producer of crude oil and the sixth largest exporter of oil within the OPEC bloc. However, virtually all chemical and petrochemical products used in the Nigerian oil and gas industry are currently imported. There is therefore the need for the Nigerian petrochemical industry to reposition itself to take advantage of these increasing market opportunities. This paper examines the strategic fit of the petrochemical industry within the value chain of the oil and gas industry, using critical petrochemical-based products as examples.
\end{abstract}

Keywords: Petrochemicals, Vertical Integration, Oilfield Chemicals, Oil and Gas, NNPC

\section{Introduction}

The application of chemical principles represents the most reasonable and economical ways of utilizing natural resources to convert often cheap, large-tonnage raw materials into commercial products, many of which are superior to the natural materials. This is value addition and it forms the cornerstone of economic and industrial development: it is getting more from less.

Oil and gas, coal and vegetable products represent the three main sources of synthetic organic chemicals [1]. While each of these raw materials has its own peculiar advantages, oil and gas invariably have overall advantages over coal and vegetable sources, particularly for countries richly endowed with oil and gas. Compared to vegetable products, for example, oil and gas are more readily transportable, and a given weight of oil or gas would give higher yield of synthetic chemicals than the same weight of vegetable oil. Similarly, compared to coal, oil or gas has the advantage of having carbon already combined with hydrogen, an essential component of petrochemicals.

The impact of petrochemicals is ubiquitous, permeating all facets of society from household goods to packaging, industrial and pharmaceutical products. Petrochemicals also find extensive applications in the oil and gas industry, the very precursor of petrochemicals. Indeed, for a nation endowed with oil and gas resources, a well-structured petrochemical industry represents the highest level of value addition to such resources. Therefore, the petrochemical industry should be one of the most important sectors deserving utmost attention, particularly given the multiplier effects of this industry to the economic and industrial development of the nation.

In this paper, we highlight the applications of petrochemicals in oil and gas operations. To this end, we shall examine the structure of the Nigerian petrochemical industry vis-à-vis the structure of a conventional petrochemical industry. The aim is to identify any structural misalignments that might be limiting the impact of the Nigerian petrochemical industry on the economic and industrial development of Nigeria in general; and on the oil and gas industry in particular.

\section{The Structure of a Conventional Petrochemical Plant}

Modern petrochemical plants are characterized by continuous operations and very expensive to build; with the capital cost of the plant representing a high proportion of the total manufacturing cost. Consequently, the plant size tends to be large and complex to maximize the economy scale. Furthermore, the petrochemical plant is typically situated 
close to a refinery as a source of feedstock or may be connected by pipeline to its source of raw materials, which may be an oil refinery or natural gas field.

The oil and gas industry provides six major building blocks for the petrochemical industry, including methane, ethylene, propylene, acetylene, butylenes, and aromatic hydrocarbons. Ethylene, propylene, acetylene and butylenes constitute the so-called Olefins. In terms of tonnage, ethylene and propylene are the most important building blocks of basic organic chemicals, with ethylene accounting for about $30 \%$ of all petrochemicals [3].
An important consideration in the design of conventional petrochemical plant is emphasis on vertical integration; that is, organization of products along family-tree lines. Through forward vertical integration, a given petrochemical plant is able to increase the percentage of captive utilization of its intermediate products since, as a rule, unit profits are higher at the finished-product end of the chain. The concept of vertical integration is exemplified in Figures 1 to 4 , which show the range of products that can be derived from methane, ethylene, propylene and butylenes, respectively [1 - 7].

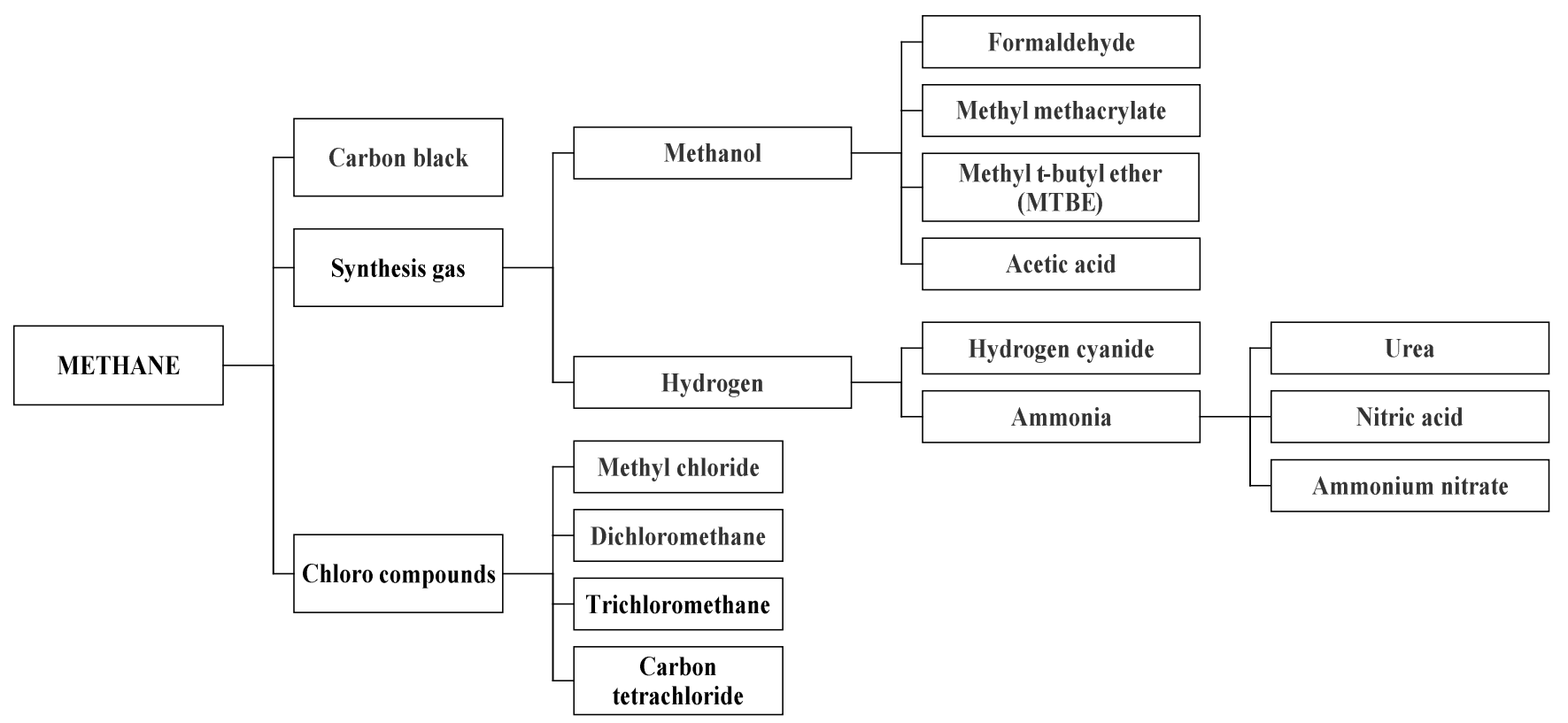

Figure 1. Typical petrochemical products derivable from Methane [Adapted from Refs 1 - 7] 


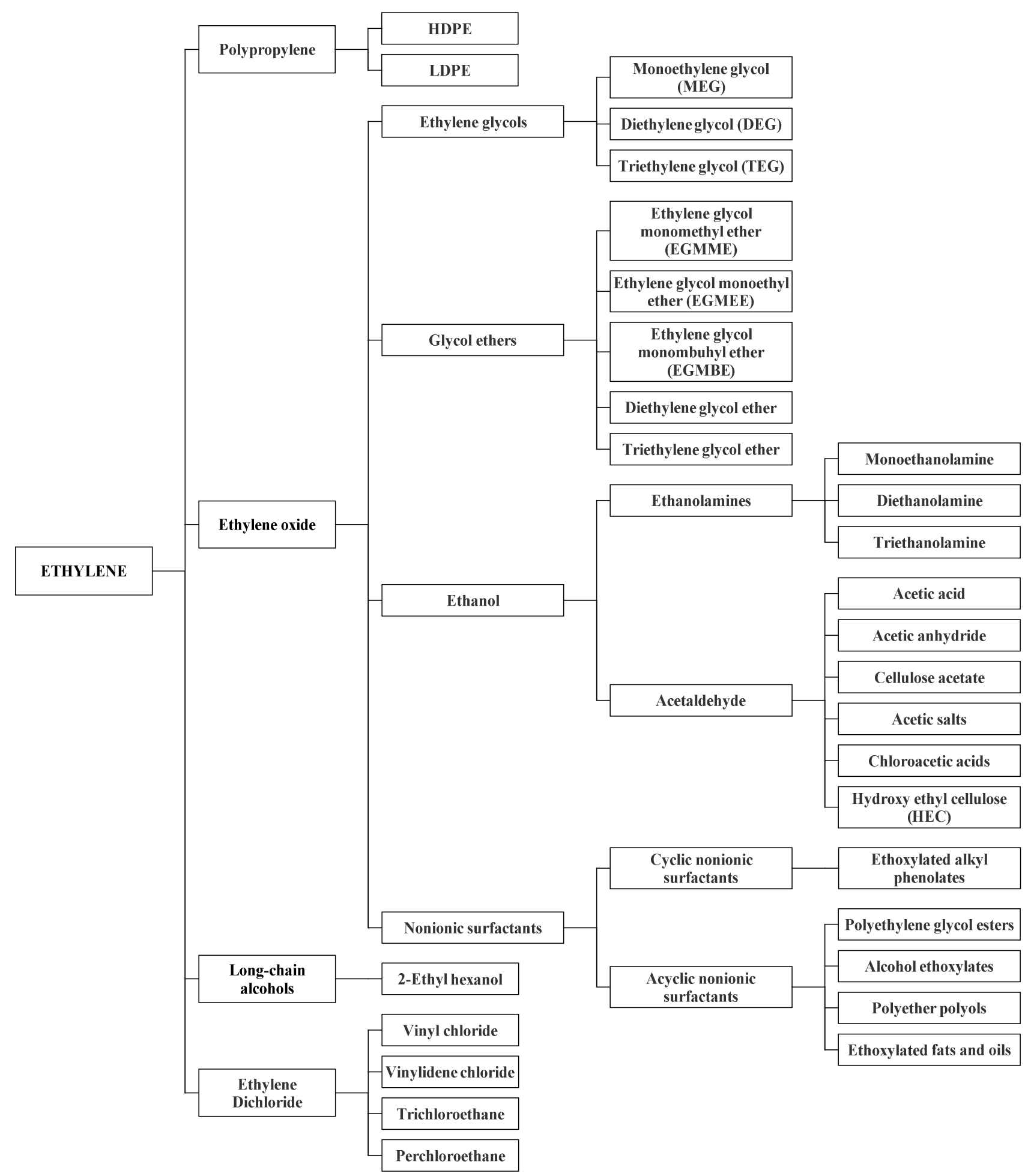

Figure 2. Typical petrochemical products derivable from Ethylene [Adapted from Refs 1 - 7]

\section{The Nigerian Petrochemical Industry}

The idea of setting up petrochemical plants in Nigeria was hatched in the early 1980s. A major policy driver for the petrochemical plants included the need to diversify and transform the economy, leading to economic stability and considerable foreign exchange savings. About $40 \%$ of the country's raw material imports have a petrochemical base, and local production of these products would cut the import expenditure by about $\$ 150$ million per year [8]. A second policy driver was the need to usefully harness more than 1 billion $\mathrm{m}^{3}$ of natural gas that was flared daily, due to lack of local market and of export facilities. Furthermore, there was the need to optimize the processes of the Warri and Kaduna refineries which came on stream in 1978 and 1980, respectively. 


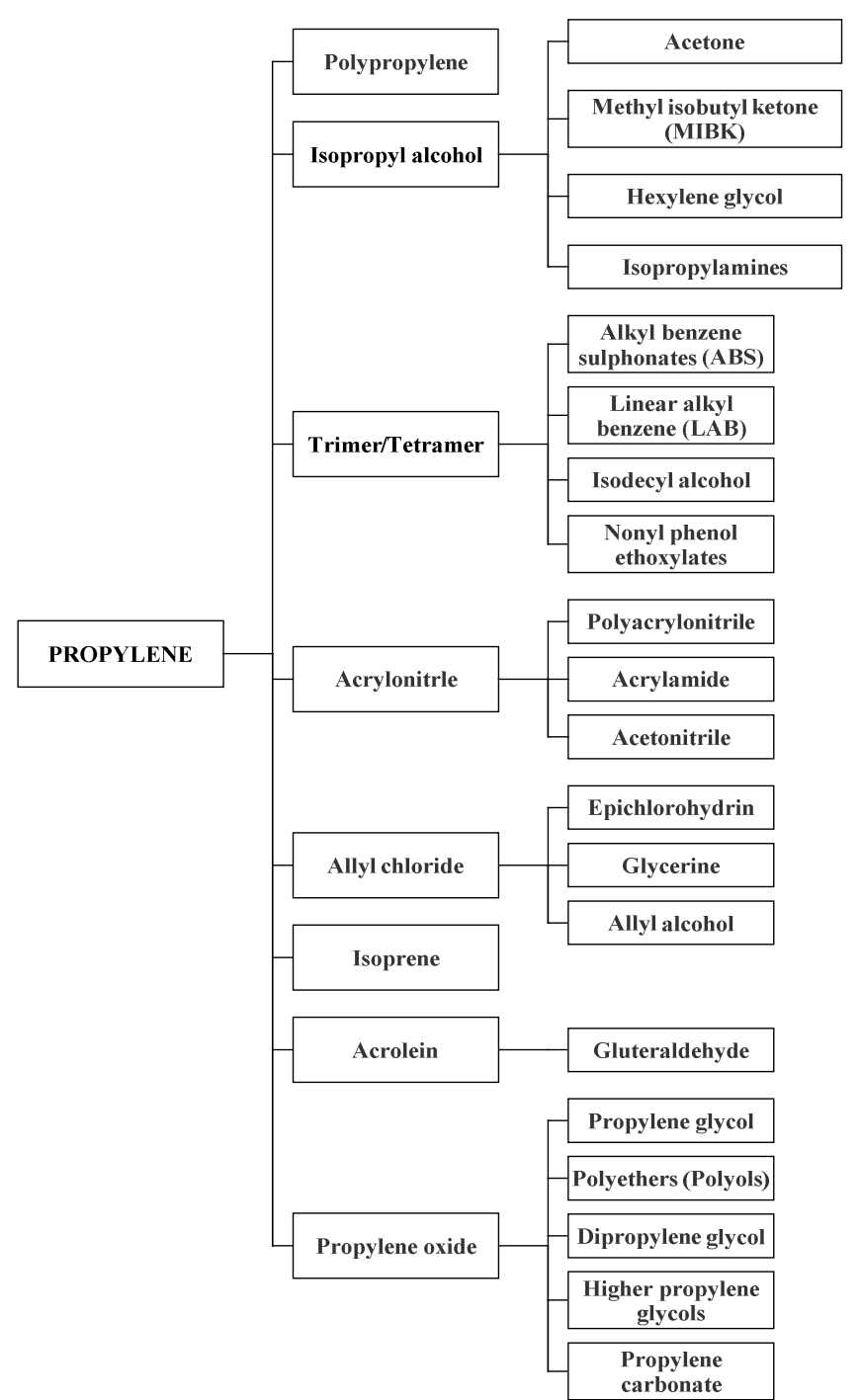

Figure 3. Typical petrochemical products derivable from Propylene [Adapted from Refs 1 - 7]

There are currently three petrochemical plants in Nigeria, including the Kaduna refinery and petrochemicals company (KRPC), Warri refinery and petrochemicals company (WRPC) as well as Indorama Eleme petrochemicals company (IEPC). The petrochemical plants in Kaduna (KRPC) and in Warri (WRPC) are subsidiaries of the Nigerian National Petroleum Corporation (NNPC); these plants came on stream in 1988. Eleme petrochemicals plant, which came on stream in 1995, was also state owned until 2006 when it was privatized and Indorama Group took over its management as a core investor. Figure 5 summarizes the products of these three petrochemical plants [9-12].

A cursory look at the Nigerian petrochemical industry as summarized in Figure 5 would reveal some structural defects in the industry right at the planning stage. In particular, there is little vertical integration in the various plants, particularly in the case of Warri refinery and petrochemical company
(WRPC) and Indorama Eleme petrochemicals company (IEPC). In the case of WRPC, for example, it is not clear if it was intended to grow into a propylene-based plant and all the various chemical products derivable from propylene; or whether it was intended to be a methane/syngas plant. If it was intended to be a propylene-based plant, then integrating it vertically would maximize the economic and technological benefits accruable from such integration. Furthermore, it is not clear what the economic benefit there is in having both WRPC and IEPCL manufacture a common product, polypropylene, when a single, much larger plant could have been built and vertically integrated for maximum profitability through economy of scale.

If, on the other hand, WRPC had been integrated vertically as methane/syngas-based plant, it would have had the capability to produce not just carbon black; but would also produce high-value and industrially essential products such as methanol, acetic acid, hydrogen, hydrogen cyanide, ammonia, urea, etc.; as outlined in Figure 1. In this regard, Nigeria missed the opportunity of pioneering the production of methanol within the West African sub-region to Equatorial Guinea, where the Bioko Methanol plant has been producing 900,000 MT per annum of chemical-grade methanol since 2001. As would be shown subsequently in this paper, methanol is one of the largest tonnage petrochemicals consumed in the oil and gas industry, where it is extensively used to prevent hydrates formation.

On the hand, there is some level of vertical integration with Kaduna refinery and petrochemical company (KRPC) in the sense that kerosene serves as the alkyl group that is combined with benzene to produce linear alkyl benzene (LAB). Nevertheless, there is a fatal flaw in this structure, namely, LAB in itself has no practical use unless it is further reacted with sulphuric acid to produce linear alkyl benzene sulphonic acid or its neutralized sodium salt that is used in the manufacture of detergents. Given that KRPC uses sulphuric acid extensively in its processes, it is rather surprising that the sulphonation of LAB to yield the much higher-value acid is left to the customer (detergent manufacturer) to carry out. Clearly, this structural defect significantly limits the customer-base of KRPC for LAB as well as impacts on its own profitability. Again, as would be shown later in this paper, linear alkyl benzene sulphonic acid, also known as dodecyl benzene sulphonic acid (DDBSA) and its neutralized salts are extensively employed in the formulation of demulsifiers and hard surface cleaners (rig wash). Therefore with just a little further vertical integration by KRPC to produce DDBSA, the profitability of that plant would significantly increase while the price of detergents to the end-user should fall, since the unit process of sulphonating LAB would no longer be carried out by the detergent manufacturer. That would also significantly encourage local cottage chemical industries involved in the manufacture of oilfield chemicals. 


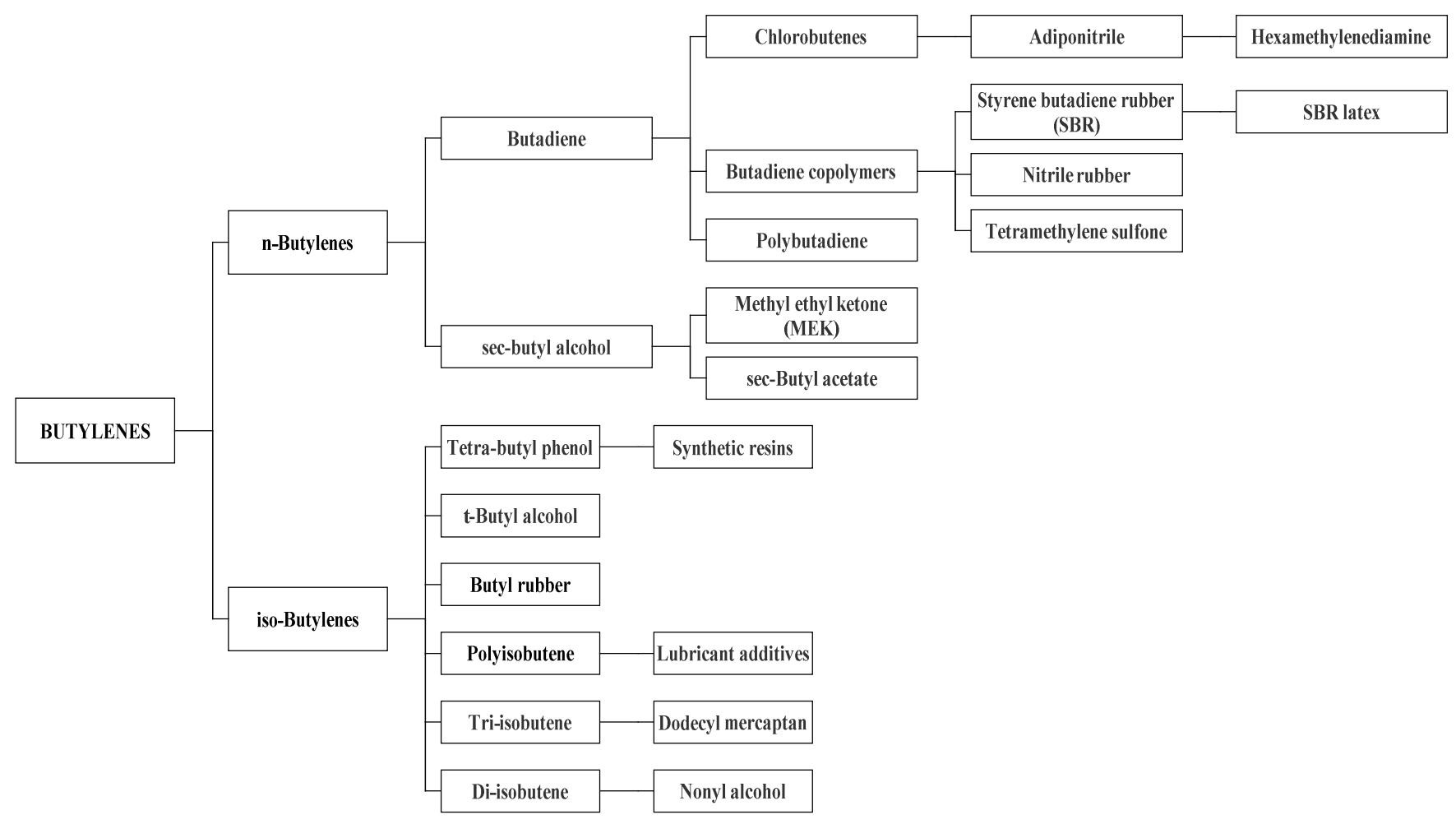

Figure 4. Typical petrochemical products derivable from Butylenes [Adapted from Refs 1-7]

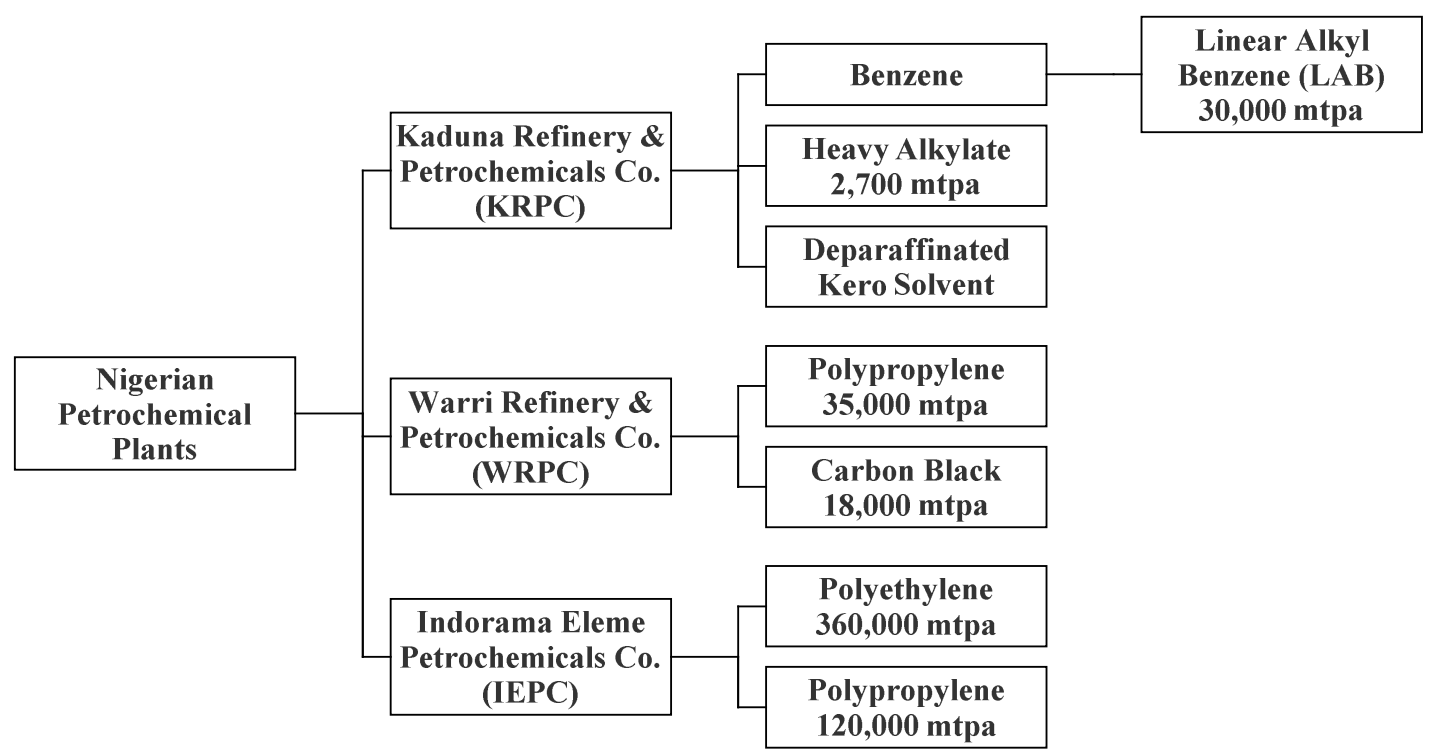

Figure 5. The structure of the Nigerian petrochemical industry [Adapted from Refs 9-12]

Similarly, the lack of vertical integration is again immediately apparent in the case of the Indorama Eleme petrochemicals company (IEPC). Rather than producing just polyethylene and polypropylene, it would seem structurally and economically reasonable to fully integrate the plant vertically, incorporating the corresponding by-products such as ethylene oxide, ethylene glycol, vinyl chloride, polyvinyl chloride, 2-ethyl hexanol, phthalic acid, phthalic anhydride, etc.

It is clear from the foregoing review of the Nigerian petrochemical industry that the concept of vertical integration was not adequately taken into consideration during the planning of its various plants. However, since the industry is relatively still in its infancy, it should be possible to correct any identifiable limitations or constraints to maximize the potentials of this important industry. Indeed, at conception, the long-term objective of the Eleme petrochemicals plant was ultimately produce ethylene oxide, ethylene glycol, terephthalic acid, polyethylene terephthalate, iso-propanol, 2-Ethyl Hexanol, caustic soda, chlorine, polyvinyl chloride, xylene and phthalic anhydride [9]. 


\section{Applications of Petrochemicals in the Oil and Gas Industry}

\subsection{Introduction}

From drilling through to refining and distribution, petrochemicals play important roles to the success of processes and operations within the value chain. The role of petrochemicals is often invisible, but the effects are visible. In this section, we shall briefly look at some of petrochemicals employed to enhance oil and gas operations throughout the value chain.

\subsection{Drilling and Completions}

Some of the petrochemicals used in drilling and completions operations include gluteraldehye, carboxy methyl cellulose (CMC), hydroxyl ethyl cellulose (HEC) and corrosion inhibitors. Gluteraldehyde which is a by-product of propylene value chain is used as a biocide against a wide range of micro-organisms, including sulphur-reducing bacteria, during completions operations. It is a constituent of packer fluids. CMC, on the other hand, is used as fluid loss controlling agent during drilling while HEC is employed as a viscosifier. Corrosion inhibitors used as packer fluids during completion operations often incorporate petrochemical-based surfactants in their formulations as well glycol ethers as adjuvants. It can be seen from Figure 5 that none of the petrochemicals highlighted in this section are currently produced by any of the Nigerian petrochemical plants.

\subsection{Production}

From injection water treatment through flow assurance and effluent water treatment, petrochemicals find extensively applications. Certain scale inhibitors used in the treatment of injection water incorporate polyacrylates in their formulations, while nonyl phenol ethoxylates derived from the Tetramer of propylene are an essential component of most demulsifier formulations. Similarly, ethoxylated alkyl phenolates derived from ethylene oxide, as well dodecyl benzene sulphonic acid (DDBSA) are widely used in demulsifier formulations. On the other hand ethoxylated fatty amines as well glycol ethers are often employed as adjuvants in formulation of wax controlling products. In terms of tonnage, methanol is by far the most widely consumed petrochemical in the production of oil and gas, particularly in deep-water operations. Several tones of methanol are daily injected at the well heads of such operations to prevent the formation of gas hydrates and its disastrous consequences. Produced water often contains residual oil, posing an environmental risk to aquatic life. Certain water clarifiers used in treating oily water contain polyacrylamide as part of their formulation.

\subsection{Gas Processing}

Prior to export or local consumption, natural gas is first treated to remove associated moisture and acidic components such as carbon dioxide and hydrogen sulphide. Triethylene glycol (TEG) is the most widely used desiccant for drying the gas owing to hygroscopic nature of this ethylene oxide by-product. In terms of tonnage, TEG is probably second only to methanol. In order to remove acidic compounds in natural gas, diethanolamine, again a by-product of ethylene oxide, is employed for this. The Nigerian petrochemical industry currently does not produce any of these products.

\subsection{Transportation}

One of the greatest flow assurance problems in deep offshore oil and gas operations is the risk of hydrates formation in subsea flow lines. In order to mitigate this, methanol is often used in large quantities as a relatively cheap and effective hydrates inhibitor. In this case, methanol act a thermodynamic inhibitor by lowering the temperature envelope below which hydrates can form within the system.

\subsection{Refining}

Despite the dehydration of crude carried out prior to exporting for refining, residual emulsion containing water and salt. Both water and salt are highly undesirable in refinery operations since water reduces the throughput of the refinery on the one hand, while salt is a highly corrosive agent, often resulting in localized corrosion in refinery process equipment with disastrous consequences. For these reasons, crude oil arriving at the refinery is invariably treated with desalting demulsifiers often containing alkyl phenol ethoxylates derived from ethylene oxide as part of their formulation. On the other hand, traces of water in refined products result in hazy appearance and therefore loss of aesthetics of the product. In order to overcome this problem, dehazing chemicals often containing glycol ethers are added to refined petroleum products.

\subsection{Distribution}

In temperate climate or during wintery conditions, temperatures often plummet to subs-zero levels which could result in flow assurance problems such as product gelling or pipeline clogging. Consequently, anti-freezing agents such as glycol ethers are often added in small dosages to petroleum products prior to dispatching through flow lines. Such glycol ethers also improve cold-start as in the case of gasoline.

\section{Conclusions}

An analysis of the Nigerian petrochemical industry vis-à-vis the structure of a conventional petrochemical industry has revealed a key structural defect arising from failure to deliberately incorporate vertical integration at the planning stage. Over the years this defect has grossly undermined the potential impact of this industry to the economic and industrial development of the nation. A further consequences of this defect is the fact that no chemical product derivable from petrochemicals that is used in the oil and gas industry is currently produced by any of the three petrochemical plants in Nigeria, thereby significantly 
contributing to capital flight through importation from other countries. This apparent defect, however, provides an opportunity to align these plants towards diversifying the range of products, thereby maximizing market share.

\section{References}

[1] R. F. Goldstein and A. L. Waddams, The Petroleum Chemicals Industry, London: Spon, p.136, 1967.

[2] K. Weissermel, and H. J. Arpe, Industrial Organic Chemistry. Weinhein: VCH, p.63, 1993.

[3] A. W. G. Hahn, The Petrochemical Industry, New York: McGraw-Hill, p.10, 1970.

[4] R. T. Nye, Chemicals from Oil, London: Pergamon Press, p.18, 1970

[5] D. M. Samuel, Industrial Chemistry - Organic, London: The Royal Society of Chemistry, p.11, 1972.
[6] J. A. Kent (Ed.), Regiel's Handbook of Industrial Chemistry, New York: Van Nonstrand Reinhold, p.539, 1992.

[7] G. A. Olah, A. Goeppart and G. K. S Prakash, Beyond Oil and Gas: The Methanol Economy, Darmstadt: Wiley-VCH Verlag GmbH \& Co.; p.209, 2006.

[8] P. Blackburn, Crude-oil slump adds to Nigeria's CPI woes, Chemical Engineering, vol. 93, p. 20E, July 21, 1986.

[9] NNPC Bulletin on Sectors of the Nigerian National Petroleum Corporation, undated.

[10] NNPC Bulletin on Petroleum Exploration and Development in Nigeria, undated.

[11] NNPC Bulletin on Warri Refining and Petrochemicals Company, undated.

[12] NNPC Bulletin on Benzene Plant Kaduna, undated. 